\title{
Effects of Roof Tile Waste-Coarse Aggregate and High Temperature History at Early Ages on Shear Strength of Reinforced Concrete Beams Made of Portland Blast-Furnace Slag Cement Type B
}

\author{
Akihiro Fujiyama ${ }^{1 a}$, Mwangi M. Macharia ${ }^{1 b}$, Yuko Ogawa'c, Kenji Kawai ${ }^{1 d}$, and Ryoichi \\ Sato $^{1 e}$ \\ ${ }^{1}$ Department of Civil and Environmental Engineering, Hiroshima University, JAPAN. \\ ${ }^{1 a}$ Email: <m153545@hiroshima-u.ac.jp>, ${ }^{1 b}$ Email: < macharia-mwang@hiroshima-u.ac.jp >, \\ ${ }^{1 c}$ Email: <ogaway@hiroshima-u.ac.jp>, ${ }^{1 d}$ Email: <kkawai@hiroshima-u.ac.jp>, ${ }^{1 e}$ Email: \\ <sator@hiroshima-u.ac.jp>.
}

\begin{abstract}
The present study aims at investigating the effects of roof tile (porous ceramic) waste-coarse aggregate (PCCA) as an internal curing agent and high temperature history at early ages on mechanical properties of concrete and shear strength of reinforced concrete (RC) beams made from Portland blast-furnace slag cement type B. The PCCA, which has a crushing value of $20 \%$ and a high water absorption of approximately $9 \%$, has been reported to be effective in mitigating autogenous shrinkages and improving the mechanical properties of concrete. Two types of concretes, one with 10 vol.\% replacement with PCCA and the other with no replacement, were prepared. Eight RC beams were prepared and two beams each were tested for two temperature conditions, namely, high temperature at early age and room temperature. The former simulates temperature history in mass concrete. The water to cement ratio was $50 \%$. All specimens were sealed immediately after casting up to the loading test ages.

The results showed that the compressive and splitting tensile strengths of concretes with PCCA were higher than those of concrete without PCCA at the temperature adjusted age of 30 days. However, at the loading age of RC beams, since the temperature adjusted concrete age differed between the two types of concretes, the effect of PCCA was not observed. Under both temperature conditions, the autogenous shrinkage strains of concretes with PCCA were lower than those of concretes without PCCA at the loading age. The shear strength of RC beams without PCCA under high temperature at early ages were lower than those without PCCA under normal temperature condition. However, in the case where PCCA was used, this decrease was mitigated through internal curing effect of PCCA.
\end{abstract}

\section{INTRODUCTION}

The autogenous shrinkage of concrete using Portland blast-furnace slag cement type B (hereafter, BB) is known to be larger than that using ordinary Portland cement especially when subjected to high temperature due to hydration heat of cement [Miyazawa et al. 2008]. It has been also reported that the autogenous shrinkage of $\mathrm{BB}$ concrete (hereafter, $\mathrm{BBC}$ ) under high temperature at early age increases up to almost twice as large as that of $\mathrm{BBC}$ cured at $20^{\circ} \mathrm{C}$, independently of the water to cement ratio [Miyazawa et al. 2008]. 
Besides, autogenous shrinkage has been reported to reduce the shear strength of RC beams [Sato and Kawakane 2008], and therefore it may be important to mitigate its effects for better performance.

On the other hand, about 150,000 tons of "Sekishu Kawara", which is a roof tile made of clay, is produced in Chugoku district of Japan. About $10 \%$ of Sekishu Kawara is demolished due to thermal cracking and expected to be recycled. This waste material has a crushing value (BS 812) of around 20\%, which is an intermediate value between artificial light weight aggregate (about $40 \%$ ) and natural aggregate (about 10\%) and a relatively high water absorption of approximately $9 \%$. For these properties, this waste material designated as porous ceramic coarse aggregate (PCCA) has been reported to be effective as an internal curing agent in mitigating autogenous shrinkages and improving the mechanical properties of concrete [Sato et al. 2011].

In the present study, the effect of internal curing with PCCA on mechanical properties and the autogenous shrinkage of $\mathrm{BBC}$ and the shear strength of RC beams subjected to the effect of high temperatures at early ages was investigated.

\section{EXPERIMENTAL INVESTIGATION}

Materials. Table 1 lists the properties of materials used in this study. Portland blast-furnace cement type $\mathrm{B}$ was used as cementitious material. Crushed sand was used as fine aggregate and crushed stone was used as coarse aggregate. PCCA with water absorption of $9.20 \%$ was used as internal curing agent in saturated and surface-dry condition after immersion for 7 days in water.

Table 1. Material properties

\begin{tabular}{|c|c|c|c|}
\hline Materials & Type & Notation & Properties \\
\hline \hline Cement & $\begin{array}{c}\text { Portland blast-furnace } \\
\text { cement type B }\end{array}$ & BB & $\begin{array}{c}\text { Density }: 3.04 \mathrm{~g} / \mathrm{cm}^{3} \\
\text { Specific surface area }: 3760 \mathrm{~cm}^{2} / \mathrm{g}\end{array}$ \\
\hline \multirow{2}{*}{ Fine aggregate } & Crushed sand & $\mathrm{S}$ & $\begin{array}{c}\text { Density }: 2.58 \mathrm{~g} / \mathrm{cm}^{3} \\
\text { Water absorption: } 1.56 \%\end{array}$ \\
\hline \multirow{2}{*}{ Coarse aggregate } & Crushed stone & $\mathrm{G}$ & $\begin{array}{c}\text { Density: } 2.62 \mathrm{~g} / \mathrm{cm}^{3} \\
\text { Water absorption: } 0.59 \%\end{array}$ \\
\cline { 2 - 4 } & $\begin{array}{c}\text { Porous ceramic coarse } \\
\text { aggregate }\end{array}$ & PCCA & $\begin{array}{c}\text { Density: } 2.26 \mathrm{~g} / \mathrm{cm}^{3} \\
\text { Water absorption }: 9.20 \%\end{array}$ \\
\hline
\end{tabular}

Mixture proportions. Table 2 tabulates the mixture proportions of the two types of concretes in this study. The water to cement ratio is $50 \%$ and the unit water content is $170 \mathrm{~kg} / \mathrm{m}^{3}$. Sand-total aggregate ratio (s/a) is $44.6 \%$. G10 denotes BBC in which $10 \%$ of the total coarse aggregate volume is replaced with PCCA.

Table 2. Mixture Proportions

\begin{tabular}{|c|c|c|c|c|c|c|c|c|c|}
\hline \multirow{2}{*}{$\begin{array}{l}\text { Name of } \\
\text { specimen }\end{array}$} & \multirow{2}{*}{$\begin{array}{l}\mathrm{W} / \mathrm{C} \\
(\%)\end{array}$} & \multirow{2}{*}{$\begin{array}{c}\text { PCCA } \\
\text { replacement } \\
(\text { vol. } \%)\end{array}$} & \multirow{2}{*}{$\begin{array}{l}\text { Air } \\
(\%)\end{array}$} & \multirow{2}{*}{$\begin{array}{l}\mathrm{s} / \mathrm{a} \\
(\%)\end{array}$} & \multicolumn{5}{|c|}{ Unit content $\left(\mathrm{kg} / \mathrm{m}^{3}\right)$} \\
\hline & & & & & $\mathrm{W}$ & $\mathrm{C}$ & $S$ & $\mathrm{G}$ & PCCA \\
\hline $50 \mathrm{BBC}$ & & 0 & \multirow{2}{*}{4.5} & \multirow{2}{*}{44.6} & \multirow{2}{*}{170} & \multirow{2}{*}{340} & \multirow{2}{*}{774} & 976 & 0 \\
\hline 50G10 & & 10 & & & & & & 878 & 84 \\
\hline
\end{tabular}


Curing temperature conditions. Two curing temperature conditions were adopted: high temperature history (High) and normal temperature curing (Normal). The high temperature history simulated a temperature history inside massive concrete. The specimens were cured in a temperature control chamber where the maximum temperature was set at $70 \pm 1^{\circ} \mathrm{C}$ and the relative humidity was set at $90 \pm 5 \%$. After being subjected to the high temperature history, the specimens were removed from the temperature control chamber and sealed curing was carried out under room temperature until the test ages. In the case of the normal temperature curing, sealed curing was carried out under normal room temperatures until the test ages. Figure 1 shows the measured concrete temperatures up to the age of 20 days.

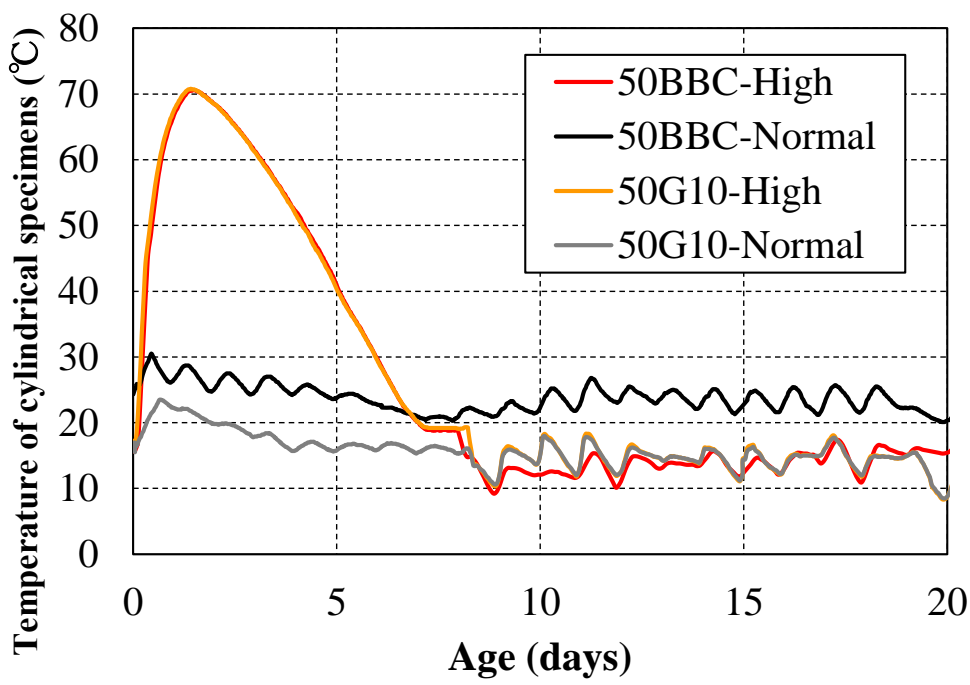

Figure 1. Temperature in the specimens

Items of investigations. Compressive strength, modulus of elasticity under compression and splitting tensile strength were investigated as mechanical properties. The tests for compressive strength and measurements of modulus of elasticity were carried out at the ages of 1, 3, 7, 28, 91 days and the loading test age of RC beams by using cylindrical specimens with a diameter of $100 \mathrm{~mm}$ and a height of $200 \mathrm{~mm}$ in accordance with JIS A 1108 and JIS A 1149, respectively. Splitting tensile strength tests were carried out at the ages of 3,7,28, 91 days and the loading test age of RC beams by using cylindrical specimens with a diameter of $150 \mathrm{~mm}$ and a height of $200 \mathrm{~mm}$ in accordance with JIS A 1113.

Figure 2 shows outline of shrinkage test specimen. The shrinkage strain of concrete with time was measured from just after placing with a strain gauge embedded at the center of $200 \times 320 \times 1000 \mathrm{~mm}$ (the same crosssectional dimension as the RC beam) concrete specimens.

Figure 3 shows outline of RC beams. The dimensions of the RC beam were $200 \times 320 \times 2300 \mathrm{~mm}$. The effective depth was $250 \mathrm{~mm}$ and the shear span length to effective depth ratio (a/d) was fixed to 3.0. The tensile reinforcement ratio was $0.8 \%$. Two RC beams were prepared for each curing temperature condition, for a total of four beams in each mixture proportion. Deflection and shear displacement of RC beam were measured using displacement transducers. All the RC beams were loaded symmetrically with two concentrated loads. Reinforcement strain at the mid-span of the RC beam, the center of the shear span and at a distance of $500 \mathrm{~mm}$ from the loading point were measured from just after placing until the loading test age. 


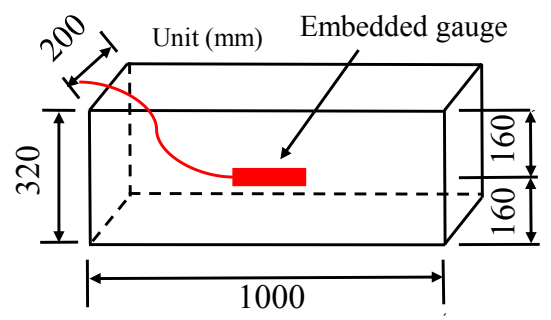

Figure 2. Outline of shrinkage
•:D16 Tension reinforcement ratio $\left(\mathrm{p}_{\mathrm{s}}=\mathrm{A} / \mathrm{bd}\right): 0.8 \%$

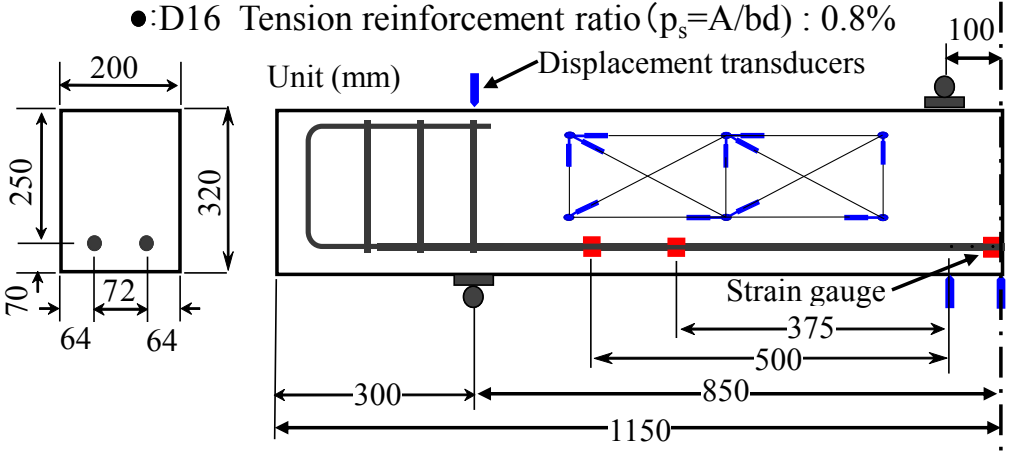

Figure 3. Outline of RC beam test specimen

\section{RESULTS AND DISCUSSIONS}

Mechanical properties. Figure 4 shows the compressive strength development with temperature adjusted age. The temperature adjusted age was obtained from Japan Society of Civil Engineers's Standard specification for concrete structures [JSCE Design 2012]. The compressive strengths of concretes cured under normal temperatures were higher than those under high temperatures history, in both the reference and the internally cured concretes. In both the curing temperature conditions, after the temperature adjusted age of 30 days, the compressive strengths of concretes with PCCA were were slightly larger than those of concrete without PCCA.

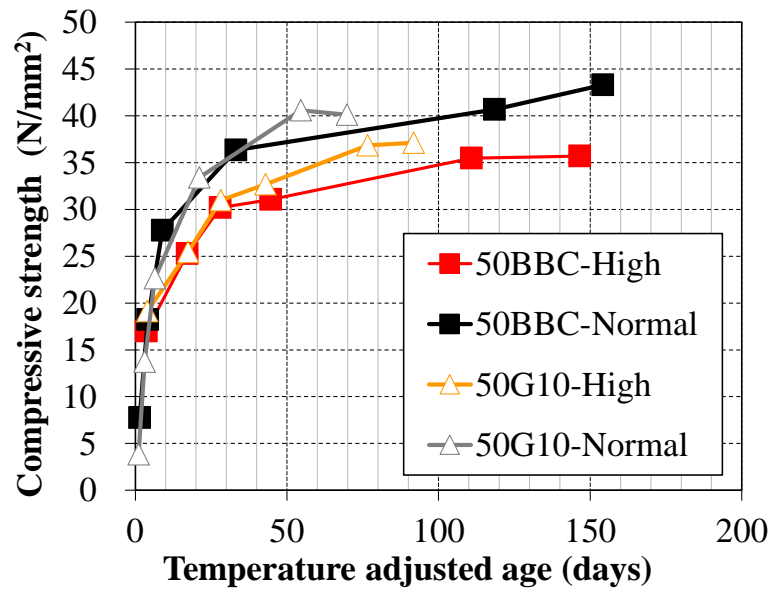

Figure 4. Compressive strengths

Figure 5 shows the splitting tensile strength development with temperature adjusted age. In the case of concretes without PCCA, the splitting tensile strengths of concretes cured under normal temperatures were higher than those under high temperatures history after the temperature adjusted ages of 40 days. In the case of concretes with PCCA, there was no remarkable difference in the splitting tensile strengths between high temperature history and normal temperature curing. In both of the curing temperature conditions, after the temperature adjusted age of 30 days, the splitting tensile strengths of concretes with PCCA were larger than those of concrete without PCCA. Figure 6 shows the relationship between splitting tensile strengths and compressive strengths, as well as the relationship obtained using JSCE formula [JSCE Design 2012]. The splitting tensile strengths of concrete were equal to or higher than those by JSCE, in both the reference and the internally cured concretes and independent of curing temperature condition. 


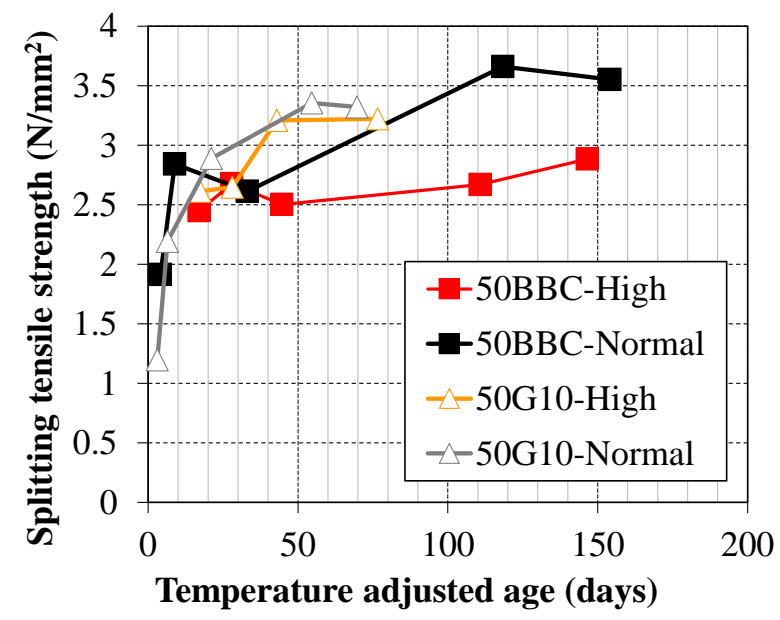

Figure 5. Splitting tensile strengths

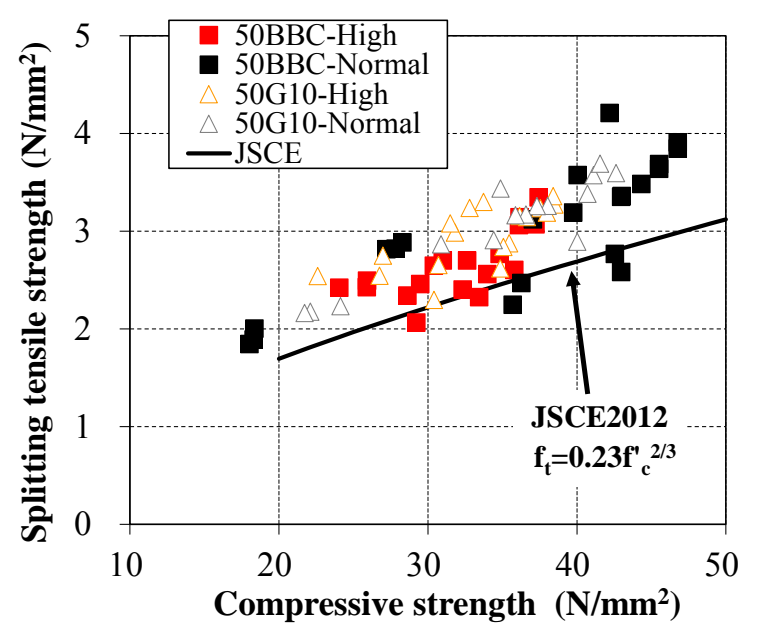

Figure 6. Relationship between splitting tensile strengths and compressive strengths

Figure 7 shows the modulus of elasticity development with temperature adjusted age. Figure 8 shows the relationship between moduli of elasticity and compressive strengths, as well as the relationship obtained using the JSCE values [JSCE Design 2012]. The moduli of elasticity of concretes cured under normal temperature were higher than those under high temperature history, in both the reference and the internally cured concretes. The moduli of elasticity of concretes with PCCA were equal to or lower than those of concrete without PCCA, in both curing temperature conditions. However, the moduli of elasticity of concrete with PCCA and without PCCA were higher than the JSCE values independent of curing temperature condition.

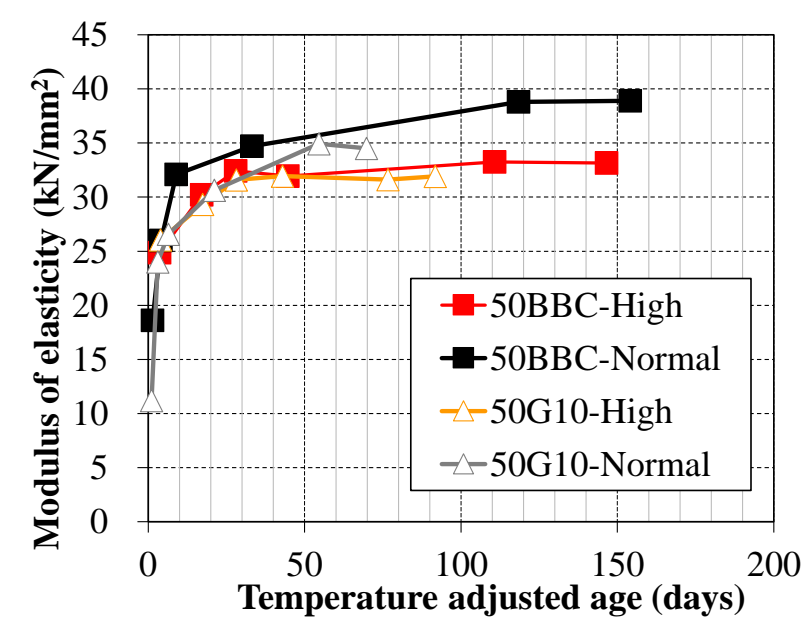

Figure 7. Modulus of elasticity

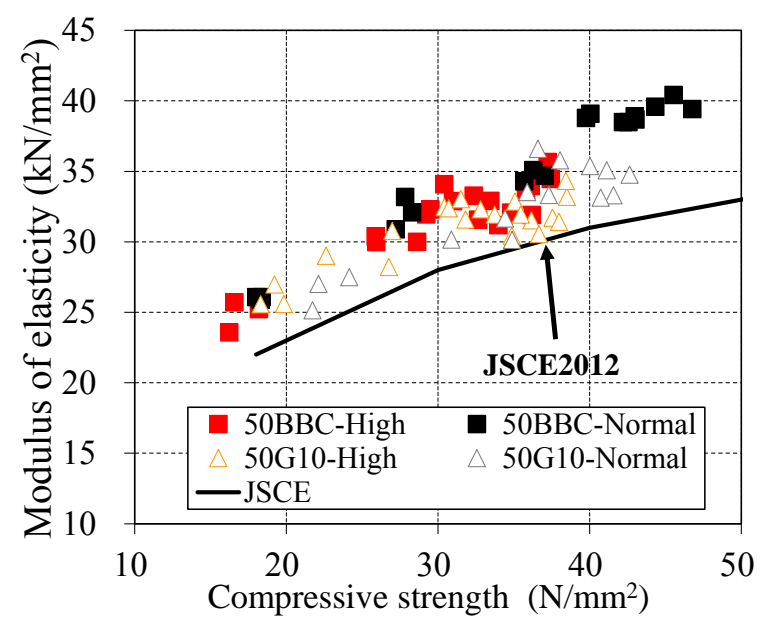

Figure 8. Relationship between moduli of elasticity and compressive strengths

Shrinkage strain in concrete. Figure 9 shows the measured strain of the shrinkage test specimens. Figure 10 shows the measured temperatures of the shrinkage test specimens. Figure 11 shows the relationship between autogenous shrinkage strain and temperature adjusted age. The autogenous shrinkage was obtained by deducting the thermal strain from the measured strain. The coefficient of thermal expansion 
of concrete used for calculation of thermal strain was $12 \mu /{ }^{\circ} \mathrm{C}$, which is the proposed value for BBC by the Japan Concrete Institute Guidline (2008). The positive side of the figure shows expansion while the negative side shows shrinkage of concretes.

According to figure 11, in the case of high temperature history, the high temperature history increases the autogenous shrinkage strain until the peak temperatures. However, the strains decrease with decrease in temperature to almost zero up until the room temperature is reached. After reaching room temperature, the autogenous shrinkage strain of concretes subjected to high temperature history is generated at a higher rate than that cured under normal temperature. After the temperature adjusted age of 100 days, the autogenous shrinkage strain of concretes subjected to high temperature history was higher than that of concretes cured under normal temperature, in both the reference and the internally cured concretes. In both curing temperature conditions, the autogenous shrinkage strain of concretes with PCCA was lower than that of concrete without PCCA until the temperature adjusted age of 200 days, probably due to the internal curing effect of PCCA. However, the autogenous shrinkage strain of concrete with PCCA was equal to or higher than that of concrete without PCCA after the temperature adjusted age of 200 days. In the case of high temperature history, the shift in autogenous shrinkage strain towards the expansion side with decrease in temperature is thought to be due to the use of a constant coefficient of thermal expansion in data reduction which might not be appropriate to correctly determine the thermal strain. The coefficient of thermal expansion of concrete and cement paste is known to change with hydration of cement at early age [Maruyama et al. 2010]. Therefore, it is necessary to consider the appropriate coefficient of thermal expansion
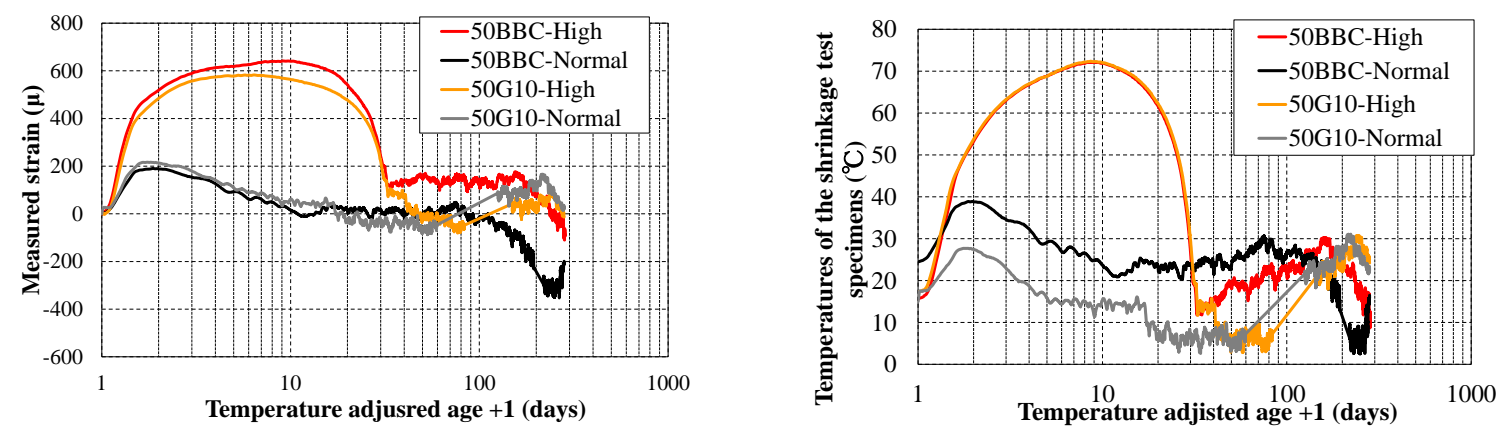

Figure 9. Measured strain Figure 10. Temperatures of the shrinkage test specimens

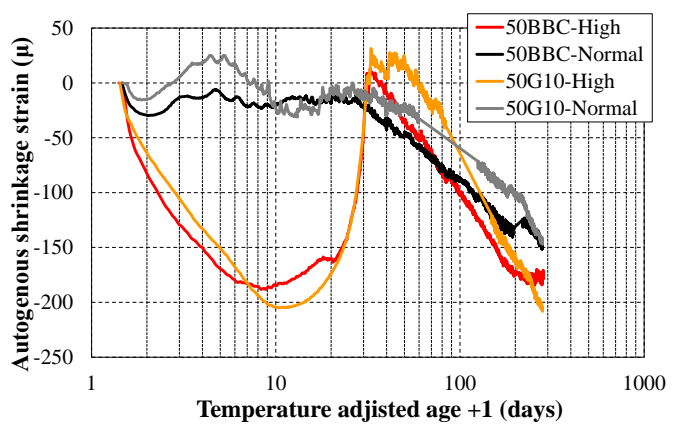

Figure 11. Shrinkage strain

Reinforcement strain. Figure 12 shows the reinforcement strain of RC beams until the loading test age. Figure 13 shows the temperature of RC beams until the loading test age. The reinforcement strain cured under normal temperatures were higher than those under high temperatures history, regardless of the PCCA replacement. In both curing temperature conditions, the reinforcement strain in concrete with PCCA were 
almost the same as those in concrete without PCCA. In the case of high temperature history, the reinforcement strains were observed to shift toward the expansion side during the temperature decrease phase. This is thought to be due to the effect of the difference of thermal expansion coefficient between reinforcement and concrete.

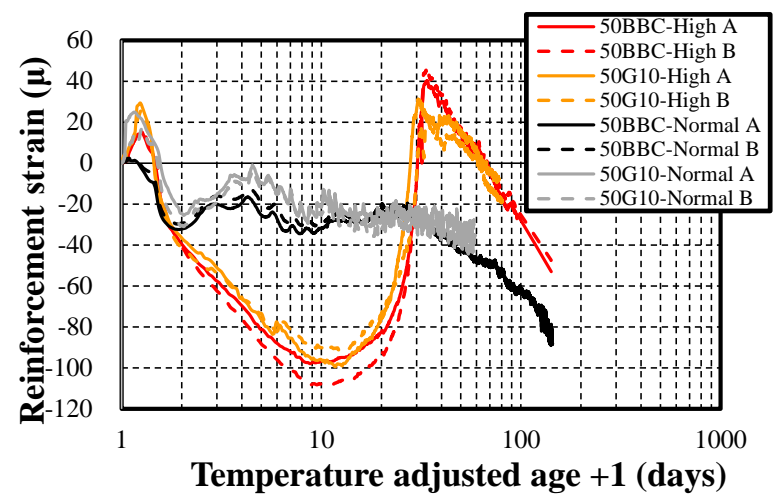

Figure 12. Reinforcement strain

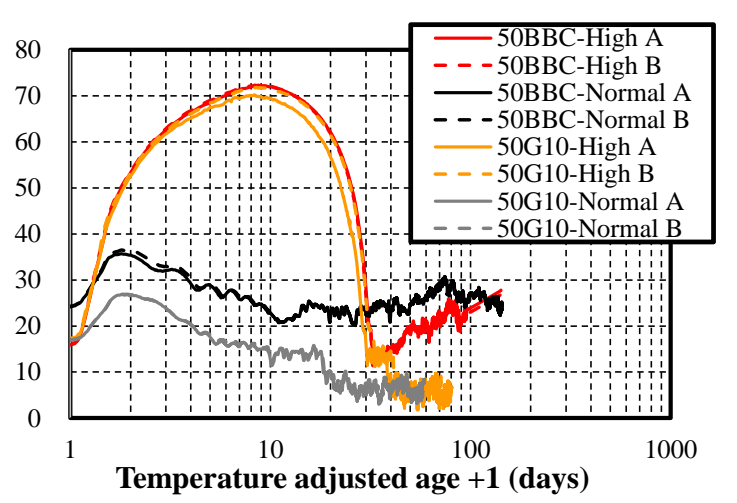

Figure 13. Temperature of RC beams

Shear strength of RC beams. Figure 14 shows the relationship between load and deflection of RC beams. Figure 15 shows the relationship between shear force and shear displacement of RC beams. Figure Figure 16 shows the relationship between shear force and diagonal displacement of RC beams. The circular marks denote the diagonal cracking. The diagonal cracking strength (shear strength) of RC beams was obatined from comparison of the point where a sharp decline in load on the load-deflection relationship was observed, and the point where a remarkable increase in the shear displacement was observed on the shear force-shear displacement relationship and the shear force-diagonal displacement relationship. Of these values, the lowest was adopted as the shear strength of RC beam. Table 3 shows outline of loading test results.

Figure 17 shows the experimental values and calculations of shear strength of RC beams. The calculations were obtained using Niwa's equation which is indicated in Eq. (1) [Niwa et al. 1986]. According to this figure, the experimental values were higher than the calculations by approximately 22 27\%, which shows that the shear strengths could be evaluated on the safe side, in both the reference and the internally cured $\mathrm{RC}$ beams, and independent of curing temperature condition.

$\tau_{c r, c a l}=0.2 f^{\prime}{ }_{c}{ }^{1 / 3}(d / 1000)^{-1 / 4}\left(100 p_{s}\right)^{1 / 3}(0.75+1.4 /(a / d))$

where, $f_{c}^{\prime}$ :compressive strength of concrete, $d$ :effective depth of RC beams, $p_{s}$ :tension reinforcement ratio, $a$ :shear span

Figure 18 shows normalized values of shear strength. According to this figure, the shear strength of RC beams under high temperature history were lower than those under normal temperature curing by approximately $5 \%$, in both the reference and the internally cured RC beams. In both curing temperature conditions, the shear strength of RC beams with PCCA were higher than those without PCCA by approximately $2 \%$, probably due to the effect of internal curing.

As shown on the right side of figure 18, when the values of shear strength of RC beams without PCCA under high temperature history were normalized by those of RC beams without PCCA under normal temperature curing, there was a decrease in shear strength of approximately 5\%. However, in the case where PCCA was used, this decrease in shear strength of RC beams was mitigated to $3 \%$, through the internal curing effect of PCCA. In the case of internally cured normal temperature RC beams, a $2 \%$ increase in the shear strength of RC beams compared to reference RC beams was observed. 

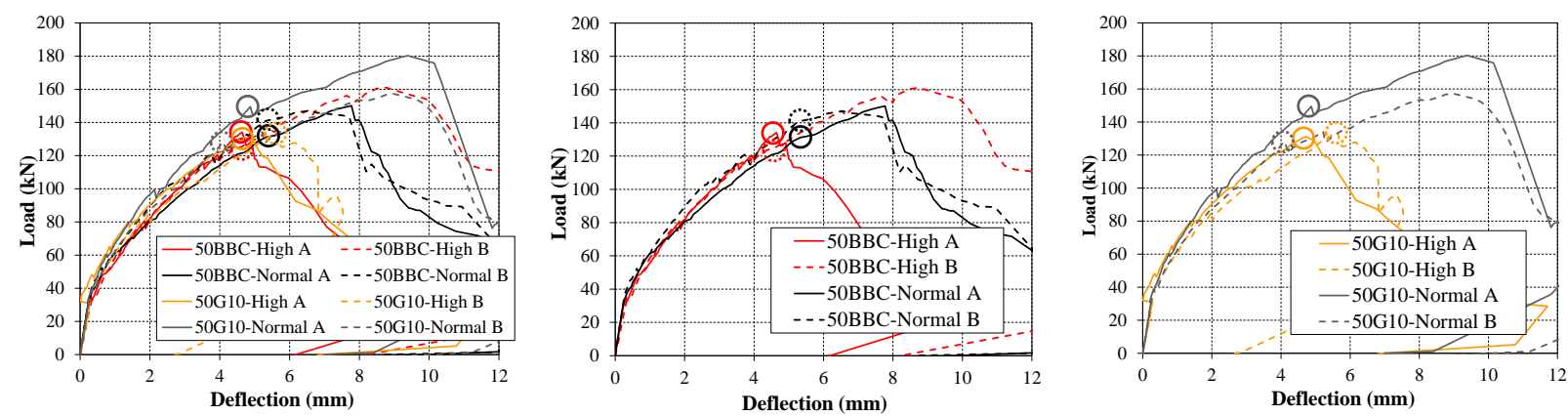

Figure 14. The load-deflection relationship
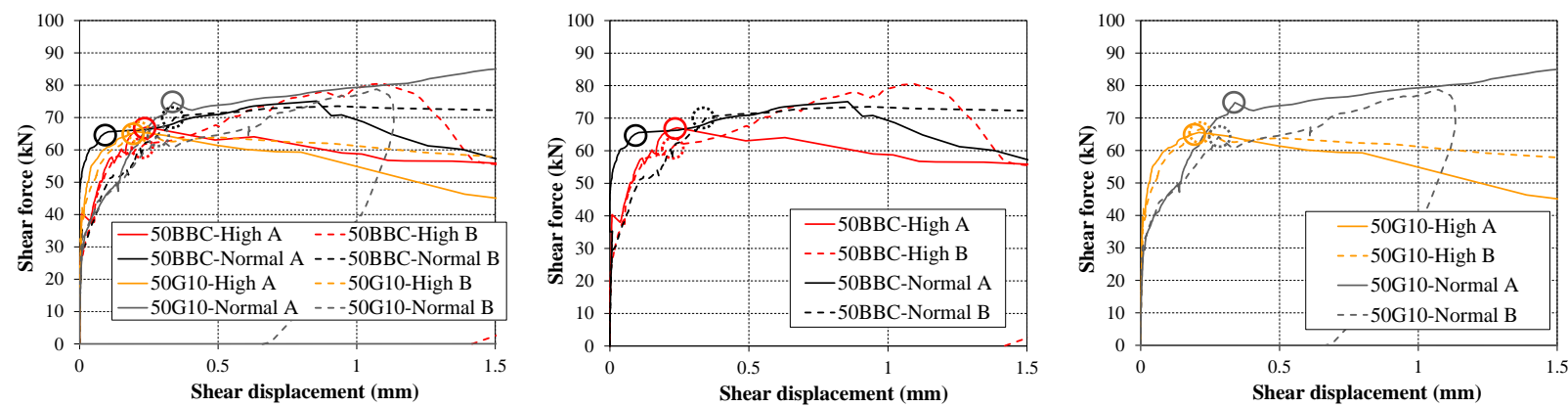

Figure 15. The shear force-shear displacement relationship
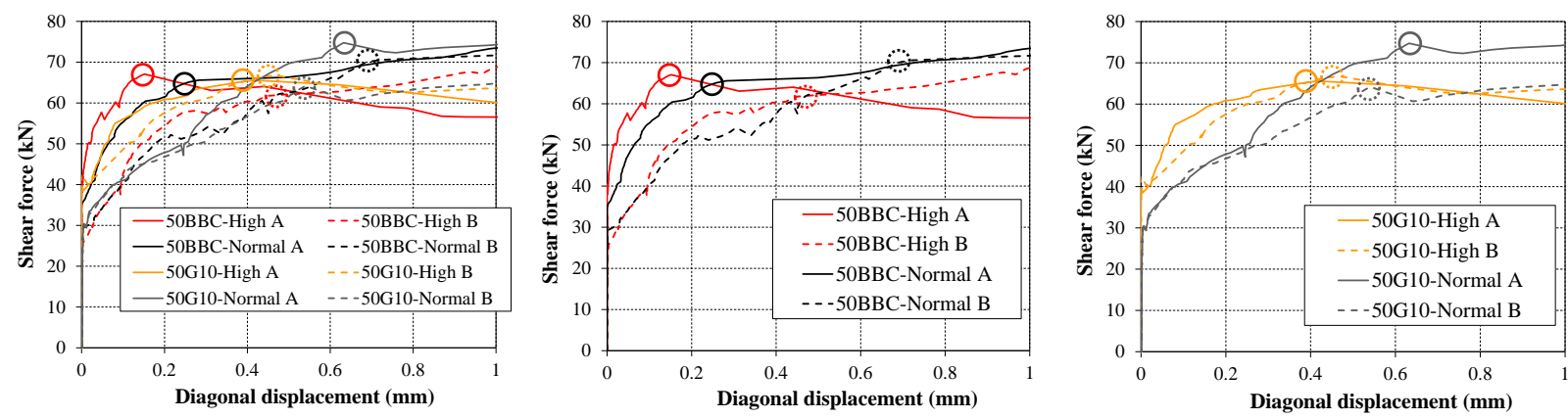

Figure 16. The shear force-diagonal displacement relationship

Table 3. Outline of loading test results

\begin{tabular}{|c|c|c|c|c|c|c|c|c|c|}
\hline \multirow{2}{*}{ Item } & \multicolumn{9}{|c|}{ Shear strength } \\
\hline & \multicolumn{6}{|c|}{ Experimental values } & \multicolumn{3}{|c|}{ Calculations (Niwa's Eq) } \\
\hline \multirow{2}{*}{ Name of specimens } & $V_{c}$ & $\tau_{c r, \exp }$ & Average & \multicolumn{3}{|c|}{ Ratio } & \multirow{2}{*}{\begin{tabular}{|l}
$\frac{V_{c, \text { calc }}}{\mathrm{kN}}$ \\
\end{tabular}} & \multirow{2}{*}{$\begin{array}{l}\tau_{c r, c a l c} \\
\mathrm{~N} / \mathrm{mm}^{2}\end{array}$} & \multirow{2}{*}{$\begin{array}{l}\tau_{c r, \text { exp }} / \\
\tau_{c r, \text { calc }}\end{array}$} \\
\hline & $\mathrm{kN}$ & $\mathrm{N} / \mathrm{mm}^{2}$ & $\mathrm{~N} / \mathrm{mm}^{2}$ & (High/Normal) & (G10orS12/BBC) & (/BBC-Normal) & & & \\
\hline 50BBC-High A & 134.1 & 1.34 & \multirow{2}{*}{1.29} & \multirow{2}{*}{0.95} & \multirow{2}{*}{1.00} & \multirow{2}{*}{0.95} & \multirow{2}{*}{104.9} & \multirow{2}{*}{1.05} & 1.28 \\
\hline 50BBC-High B & 124.1 & 1.24 & & & & & & & 1.18 \\
\hline 50BBC-Normal A & 131.2 & 1.31 & \multirow{2}{*}{1.36} & \multirow{2}{*}{1.00} & \multirow{2}{*}{1.00} & \multirow{2}{*}{1.00} & \multirow{2}{*}{111.9} & \multirow{2}{*}{1.12} & 1.17 \\
\hline 50BBC-Normal B & 141.1 & 1.41 & & & & & & & 1.26 \\
\hline 50G10-High A & 131.2 & 1.31 & \multirow{2}{*}{1.32} & \multirow{2}{*}{0.95} & \multirow{2}{*}{1.02} & \multirow{2}{*}{0.97} & \multirow{2}{*}{106.3} & \multirow{2}{*}{1.06} & 1.23 \\
\hline 50G10-High B & 133.4 & 1.33 & & & & & & & 1.26 \\
\hline 50G10-Normal A & 149.5 & 1.49 & \multirow{2}{*}{1.39} & \multirow{2}{*}{1.00} & \multirow{2}{*}{1.02} & \multirow{2}{*}{1.02} & \multirow{2}{*}{109.1} & \multirow{2}{*}{1.09} & 1.37 \\
\hline 50G10-Normal B & 128.4 & 1.28 & & & & & & & 1.18 \\
\hline
\end{tabular}




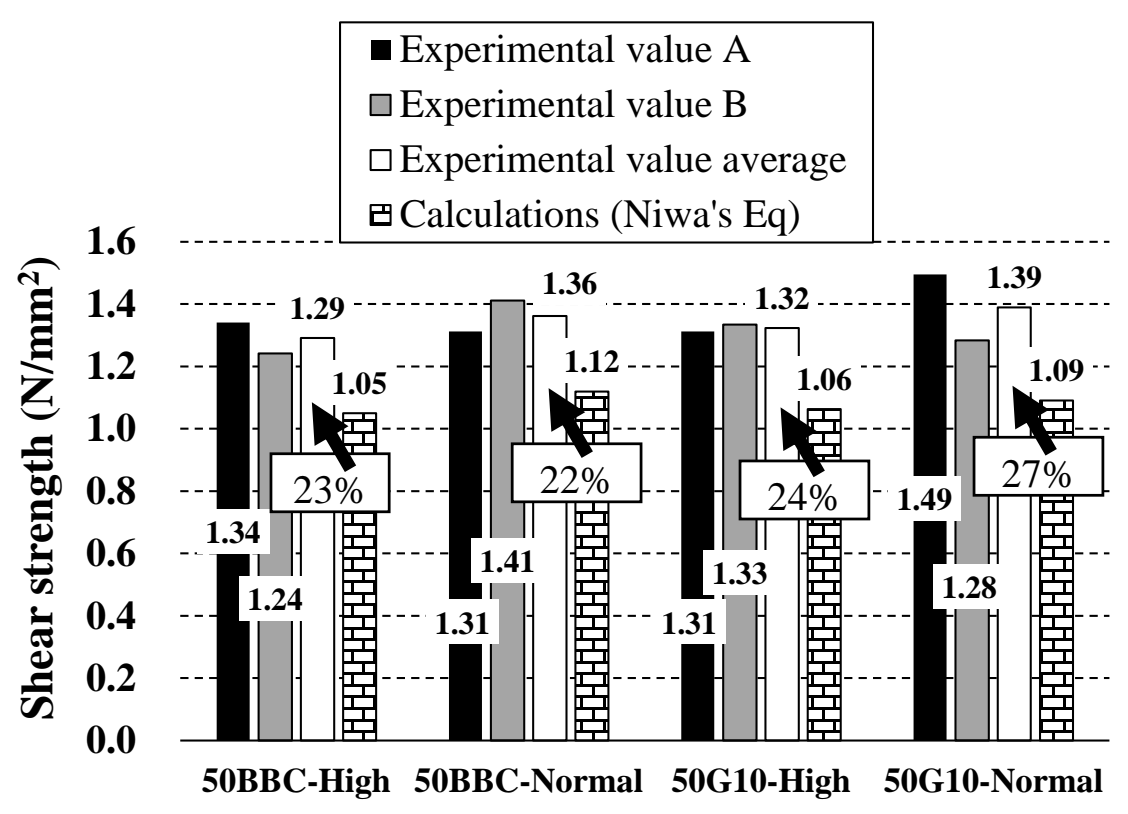

Figure 17. Shear strength of experimental

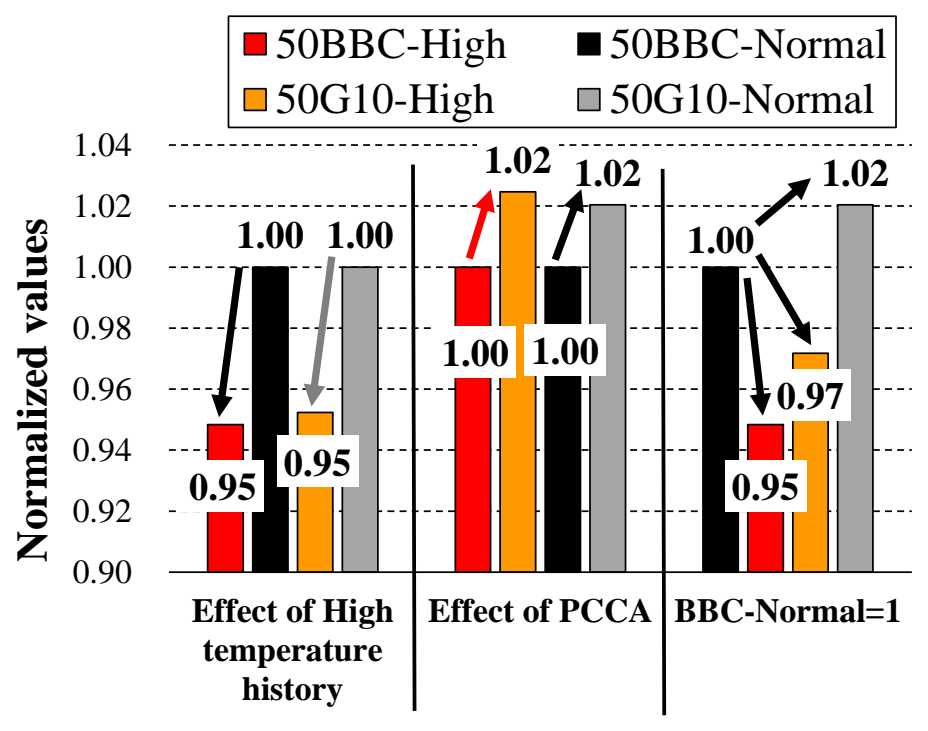

Figure 18. Normalized values of shear strength values and calculations

\section{CONCLUSION}

The present study investigated the effect of internal curing using PCCA on mechanical properties and the autogenous shrinkage of $\mathrm{BBC}$ and the shear strength of $\mathrm{RC}$ beams exposed to ambient high temperature history high temperatures history at early ages. The following conclusions can be drawn within the limits of the present experiments; 
The compressive strengths of $\mathrm{BBC}$ with PCCA were higher than those of $\mathrm{BBC}$ after the temperature adjusted age of 30 days, regardless of curing temperature conditions.

The splitting tensile strengths of BBC with PCCA were higher than those of concrete without PCCA after the temperature adjusted age of 30 days and those of BBC were equal to or higher than those by JSCE, in both the reference and the internally cured concretes and independent of curing temperature conditions.

The moduli of elasticity of BBC with PCCA were equal to or lower than those of BBC without PCCA. However, those of $\mathrm{BBC}$ were higher than those by JSCE, in both the reference and the internally cured concretes and independent of curing temperature condition.

The autogenous shrinkage strains of concretes with PCCA were slightly lower than those of concretes without PCCA until the temperature adjusted age of 200 independent of the curing temperature conditions, probably due to the internal curing effect of PCCA. However, the autogenous shrinkage strains of concretes with PCCA were equal to or higher than those of concretes without PCCA after the temperature adjusted age of 200 days. The coefficient of thermal expansion of concrete and cement paste is known to change with hydration of cement at early age. Therefore, it is necessary to consider the appropriate coefficient of thermal expansion of concrete at early ages.

The shear strength of RC beams without PCCA under high temperature history were lower than those without PCCA under normal temperature curing by approximately $5 \%$. However, in the case where PCCA was used, this decrease in shear strength of RC beams was mitigated to $3 \%$, through the internal curing effect of PCCA. In the case of internally cured normal temperature RC beams, a $2 \%$ increase in the shear strength of RC beams compared to reference RC beams was observed.

\section{REFERENCES}

Miyazawa, S., Sato, R. and Sugiyama, J. (2008) "Prediction Equation for Autogenous Shrinkage of Blast Furnace Slag Cement Concrete Subjected to Elevated Temperatures." Proceedings of the Japan Concrete Institute, Vol. 30, No.1, 465-470.

Sato, R. and Kawakane, H. (2008) "A New Concept for the Early Age Shrinkage Effect on Diagonal Cracking Strength of Reinforced HSC Beams." Journal of Advanced Concrete Technology, Vol.6, No.1, 45-67.

Sato, R., Shigematsu, A., Nukushina, T. and Kimura, M. (2011) "Improvement of Properties of Portland Blast-Furnace Slag Cement Type B Concrete by Internal Curing Using Ceramic Roof Material Waste." Journal of Materials in Civil Engineering, Vol.23, Issue 6, 777-782.

Japan Society of Civil Engineers, (2013) "Standard Specifications for concrete structures-2012, Design." 35, 39 and 107.

Japan Concrete Institute, (2008) "Outline of Guideline of Practice for Cracking Control in Mass Concrete 2008." 49.

Maruyama, I. and Teramoto, A. (2010) "Deformation and Time Dependent Thermal Expansion Coefficient of Hardened Cement Paste in Early Ages." Cement Science and Concrete Technology, Vol.63, 77-84.

Niwa, J., Yamada, K., Yokozawa, K. and Okamura, H. (1986). "Revaluation of the equation for shear strength of reinforced concrete beams without web reinforcement." Doboku Gakkai Ronbunshu, No. 372, 167-176. 